\title{
Meta-Analisis Media Pembelajaran pada Pembelajaran Biologi
}

\author{
I Ketut Surata \\ Jurusan Pendidikan Biologi IKIP Saraswati Tabanan \\ Email: ketutsurata0@gmail.com \\ I Made Sudiana \\ Jurusan Pendidikan Biologi IKIP Saraswati Tabanan \\ Email: sudiana@gmail.com \\ I Gede Sudirgayasa \\ Jurusan Pendidikan Biologi IKIP Saraswati Tabanan \\ Email: gedesudirgayasa@gmail.com
}

\begin{abstract}
Abstrak
Latar belakang metanalisis ini adalah masih banyak guru/dosen masih belum mampu mengembangkan media pembelajaran yang efektif dan efisien khususnya untuk pendidikan biologi. Sehingga perlu dilakukan analisis artikel dari hasil-hasil penelitian terdahulu untuk memahami media yang tepat untuk pembelajaran biologi. Tujuan penelitian ini adalah untuk mengetahui: (1) jenis penelitian yang terkait dengan media pembelajaran biologi; (2) effect size media pembelajaran biologi berdasarkan tingkat Pendidikan; (3) effect size media pembelajaran biologi berdasarkan jenis media; (4) effect size media pembelajaran biologi berdasarkan materi yang digunakan sebagai konten pembelajaran. Metode yang digunakan dalam penelitian ini adalah meta analisis (Glass, 1981). Hasil penelitian menunjukkan bahwa: (1) jenis penelitian yang terkait dengan media pembelajaran biologi antara lain eksperimen, R \& D, deskriptif kuantitatif dan deskriptif kualitatif; (2) effect size media pembelajaran biologi berdasarkan tingkat pendidikan terbaik pada SMP/MTs $(1,00)$ masuk kategori tinggi; (3) effect size media pembelajaran biologi berdasarkan jenis media terbaik pada multimedia $(1,00)$ masuk kategori effect size dengan pengaruh yang tinggi; (4) effect size media pembelajaran biologi berdasarkan materi terbaik pada Spermathopyta $(2,00)$ masuk kategori effect size dengan pengaruh yang tinggi. Berdasarkan simpulan tersebut dapat disarankan untuk penelitian selanjutnya sebaiknya: (1) penelitian media pembelajaran dikembangkan dengan R \& D dengan pengujian yang lebih lengkap dan lebih baik; (2) implementasi media pembelajaran terbaik diperoleh dari penelitian pada tingkat Pendidikan SMP/MTs, pada SMA dan PT dapat dilakukan analisis kebutuhan yang lebih mendalam agar media yang digunakan benar-benar efektif dan sesuai dengan psikologi dan kecenderungan pola belajarnya; dan (3) multimedia merupakan media pembelajaran yang paling efektif, multimedia selanjutnya dapat dikembangkan berupa multimedia yang daring, blended, atau berbasis android sehingga lebih mudah diakses oleh peserta didik.
\end{abstract}

Kata kunci: meta analisis, media pembelajaran, biologi

\begin{abstract}
The background of this metanalysis is that there are still many teachers / lecturers who have not been able to develop effective and efficient learning media, especially for biology education. So it is necessary to analyze the articles from the results of previous studies to understand the right media for learning biology. The purpose of this study was to determine: (1) the type of research related to biology learning media; (2) effect size of biology learning media based on education level; (3) effect size of biology learning media based on media type; (4) effect size of biology learning media based on the material used as learning content. The method used in this study is meta-analysis (Glass, 1981). The results showed that: (1) the types of research related to biology learning media include experiments, $R \& D$, quantitative descriptive and qualitative descriptive; (2) the effect size of biology learning media based on the best education level in SMP / MTs (1.00) is in the high category; (3) the effect size of biology learning media based on the best type of media in multimedia (1.00) is included in the effect size category with a high influence; (4) effect size of biology learning media based on the best material on Spermathopyta (2.00) is included in the effect size category with a high influence. Based on these conclusions it can be suggested for further research: (1) learning media research is developed with $R \& D$ with more complete and better testing; (2) implementation of the best learning media is obtained from research at the level of SMP / MTs Education, in high school and PT can be carried out in-depth needs analysis so that the media used are truly effective and in accordance with psychology and learning patterns tendencies; and (3) multimedia is the most effective learning media, multimedia can then be developed in the form of online, blended, or androidbased multimedia so that it is more accessible to students.
\end{abstract}

Keywords: meta analysis, learning media, biology

\section{Pendahuluan}

Perkembangan ilmu pengetahuan dan teknologi yang semakin pesat, menuntut dunia pendidikan harus meningkatkan mutu pendidikannya. Mutu pendidikan dapat ditingkatkan dengan mengubah pola pikir yang digunakan sebagai landasan pelaksanaan kurikulum. Dengan demikian ini dapat dimanfaatkan untuk 
mengembangkan media pembelajaran. Namun, kenyataannya masih banyak guru/dosen masih belum mampu mengembangkan media pembelajaran yang efektif dan efisien khususnya untuk pendidikan biologi. Sehingga perlu dilakukan analisis artikel dari hasil-hasil penelitian terdahulu untuk memahami media yang sesuai untuk pembelajaran biologi.

Kata media merupakan bentuk jamak dari kata medium. Media pembelajaran adalah segala sesuatu yang dapat digunakan untuk menyalurkan pesan (bahan pembelajaran), sehingga dapat merangsang perhatian, minat, pikiran, dan perasaan siswa dalam kegiatan belajar untuk mencapai tujuan belajar. Perkembangan ilmu pengetahuan dan teknologi juga sangat mempengaruhi perkembangan media pembelajaran khususnya media pembelajaran Biologi. Media pembelajaran biologi berkembang dari media berupa awetan hewan/tumbuhan, torso, gambar, video, powerpoint, multimedia interaktif, sampai saat ini pengembangan virtual reality ataupun augmented reality. Pengembangan media pembelajaran biologi saat ini juga berkembang mengarah pada pemanfaatan internet dan big data sehingga memudahkan penyebaran ilmu biologi ke seluruh penjuru dunia.

Pada meta analisis ini dilakukan studi terhadap artikel-artikel penelitian yang mebahas tentang media pemebelajaran biologi sepuluh tahun terakhir yang telah di-publish pada jurnal nasional ber-ISSN. Artikel-artikel yang digunakan semua artikel yang mebahas tentang media pembelajaran di Indonesia, dengan pencarian daring melalui SINTA dan Google Schoolar. Kemudian dilakukan klasifikasi berdasarkan jenis metode penelitian yang digunakan, jenis media, tingkat Pendidikan, dan materi yang digunakan sebagai konten dalam media yang diteliti.

Berdasarkan hal tersebut maka dirumuskan masalah penelitian meta analisis ini antara lain: (1) Jenis penelitian apa saja yang terkait dengan media pembelajaran biologi?; (2) Bagaimana effect size media pembelajaran biologi berdasarkan tingkat Pendidikan?; (3) Bagaimana effect size media pembelajaran biologi berdasarkan jenis media?; (4) Bagaimana effect size media pembelajaran biologi berdasarkan materi yang digunakan sebagai konten pembelajaran?.

\section{Metode}

Penelitian ini menggunakan metode meta-analisis dengan mengkaji beberapa artikel pada jurnal nasional. Meta-analisis bersifat kuantitatif karena menggunakan penghitungan angka-angka dan statistik untuk kepentingan praktis, yaitu untuk menyusun dan mengekstraksi informasi dari begitu banyak data yang tak mungkin dilakukan dengan metode lain (Glass, et al, 1981).

Penelitian meta-analisis ini menggunakan sampel 14 artikel pada jurnal nasional tentang media pembelajaran biologi sepuluh tahun terakhir (2010-2020). Distribusi 14 artikel subjek penelitian dapat dilihat pada kelompok-kelompok pada Tabel 1.

Tabel 1. Distribusi Sampel Artikel

\begin{tabular}{|c|c|c|c|c|c|}
\hline No. & Penelitian & Tahun & Jenis Penelitian & Jenis Media & Materi \\
\hline 1 & Setiasih \& Hakim & 2012 & R \& D & Multimedia & Ekosistem \\
\hline 2 & Utama. dkk. & 2014 & $\begin{array}{l}\text { Deskriptif } \\
\text { Kualitatif }\end{array}$ & $\begin{array}{l}\text { Media } \\
\text { pembelajaran }\end{array}$ & Pernapasan \\
\hline 3 & Ria Karno & 2015 & Eksperimen & Audio visual/Video & Sistem Gerak \\
\hline 4 & Agustina \& Sitompul & 2015 & Eksperimen & Powerpoint & $\begin{array}{l}\text { Sistem Peredaran } \\
\text { Darah }\end{array}$ \\
\hline 5 & Isnaini. dkk. & 2016 & Eksperimen & Torso & $\begin{array}{l}\text { Sistem } \\
\text { Pencernaan }\end{array}$ \\
\hline 6 & Sari. M.P. dkk. & 2017 & Eksperimen & Audio visual/Video & $\begin{array}{l}\text { Pertumbuhan dan } \\
\text { perkembangan }\end{array}$ \\
\hline 7 & Muyaroah \& Fajartia & 2017 & $R \& D$ & $\begin{array}{l}\text { Media berbasis } \\
\text { android }\end{array}$ & Biologi kelas 10 \\
\hline 8 & Prayitno \& Hidayati & 2017 & $\mathrm{R} \& \mathrm{D}$ & Edmodo Android & Mikrobiologi \\
\hline 9 & Anantyarta \& Sari & 2017 & $\begin{array}{l}\text { Deskriptif } \\
\text { Kuantitatif }\end{array}$ & Multimedia & Genetika \\
\hline 10 & Mukti \& Nurcahyo & 2017 & $\mathrm{R} \& \mathrm{D}$ & Audio visual & Pernapasan \\
\hline 11 & Arifin. dkk. & 2018 & $\mathrm{R} \& \mathrm{D}$ & $\begin{array}{l}\text { Genetic Vocabulary } \\
\text { Card }\end{array}$ & Genetika \\
\hline 12 & Tamalina \& Prabowo & 2018 & Eksperimen & Audio visual/Video & Spermathopyta \\
\hline 13 & Kurniawan. dkk. & 2018 & $\mathrm{R} \& \mathrm{D}$ & Multimedia & Reproduksi \\
\hline 14 & Nurhikmah. dkk. & 2018 & $R \& D$ & $\begin{array}{l}\text { Blended learning } \\
\text { media }\end{array}$ & Biologi kelas 11 \\
\hline
\end{tabular}

Pengkodean (coding) dalam meta-analisis merupakan syarat paling penting untuk dapat mempermudah pengumpulan dan analisis data. Oleh karena itu instrumen dalam meta-analisis ini dilakukan dengan lembaran pemberian kode (coding category). Untuk maksud tersebut, variabel-variabel yang dipakai untuk pemberian kode dan menghasilkan informasi yang diperlukan dalam menghitung besar pengaruh PBL terhadap keterampilan 
matematika adalah Nama peneliti dan tahun penelitian, Judul Penelitian, Jenjang pendidikan subyek Penelitian, Materi yang digunakan dalam penelitian, Jenis media yang dipakai, dan Variabel terikat Penelitian.

Langkah-langkah tabulasi data adalah (1) mengidentifikasi jenis penelitian dan variabel-variabel penelitian yang setelah ditemukan, dimasukkan dalam kolom variabel yang sesuai, (2) identifikasi rerata dan deviasi standar dari data kelompok eksperimen/sebelum perlakuan maupun kelompok control/setelah perlakuan untuk setiap subjek/subpenelitian yang telah dilakukan uji coba, (3) penghitungan distribusi frekuensi dan effect size dengan menggunakan rumus Glass (Glass, et al, 1981) khusus untuk data dengan pengujian, berdasarkan rerata dan deviasi standar tersebut, yaitu dengan mencari besarnya effect size $(\Delta)$ dengan jalan membagi selisih rerata kelompok eksperimen (XE) dengan rerata kelompok kontrol (XK), dengan deviasi standar kelompok kontrol (SK). Rumusnya adalah:

$$
\Delta=\frac{\bar{x} \text { eksperimen }-\bar{x} \text { kontrol }}{S D \text { kontrol }}
$$

dengan kriteria ukuran effek (Glass, et al, 1981) sebagai berikut.

- $\quad$ effect size $\leq 0,15$ efek yang dapat diabaikan

- $\quad 0,15<$ effect size $\leq 0,40$ efek kecil

- $0,40<$ effect size $\leq 0,75$ efek sedang

- $\quad 0,75<$ effect size $\leq 1.10$ efek tinggi

- $\quad 1.10<$ effect size $\leq 1,45$ efek yang sangat tinggi

- $1,45<$ effect size pengaruh yang tinggi

\section{Hasil dan Pembahasan}

Disribusi jenis penelitian dalam sampel artikel yang dilakukan meta analisis terdiri dari penelitian eksperimen, R \& D, deskriptif kualitatif dan deskriptif kuantitatif dengan sebaran frekuensi sebagai berikut (Tabel 1).

Tabel 2. Distribusi Jenis Penelitian

\begin{tabular}{clcc}
\hline No. & \multicolumn{1}{c}{ Jenis Penelitian } & Frekuensi & Frekuensi Relatif $(\%)$ \\
\hline 1 & Eksperimen & 5 & 35.71 \\
2 & R \& D & 7 & 50.00 \\
3 & Deskriptif kualitatif & 1 & 7.14 \\
4 & Deskriptif kuantitatif & 1 & 7.14 \\
\hline
\end{tabular}

Pada Tabel 2 ditunjunkan bahwa 50\% artikel tentang media pembelajaran biologi menggunakan metode R \& D, atau penelitian (Research) dan pengembangan (Development). Artinya, penelitian yang sudah masuk sebagai artikel jurnal merupakan penelitian pengembangan media pembelajaran biologi. Selain itu, 35,71\% penelitian merupakan penelitian eksperimen yang menguji kefeektifan penggunaan media pembelajaran biologi. Sisanya merupakan penelitian deskriptif. Penelitian media pembelajaran biologi lebih banyak menggunakan metode R \& $\mathrm{D}$ karena metode ini memungkinkan peneliti menghasilkan produk media dengan mempertimbangkan berbagai aspek antara lain: analisis kebutuhan pengguna (peserta didik dan dosen), pendapat ahli isi, media, maupun desain sehingga diharapkan diperoleh produk media pembelajaran yang tepat guna. Pengujian kelayakan produk untuk $\mathrm{R}$ \& D sebaiknya tidak hanya pada sebatas pendapat ahli tetapi sampai pada end user (peserta didik) dalam kuantitas yang lebih banyak sehingga data yang diperoleh lebih mewakili populasi. Produk hasil R \& D yang hanya di uji kelayakannya oleh ahli lebih lanjut dapat dilakukan penelitian selanjutnya berupa penelitian tindakan, deskriptif, ataupun menjadikan produk bahan eksperimen pembelajaran di dalam kelas.

Tabel 3. Distribusi Tingkat Pendidikan

\begin{tabular}{clccc}
\hline No. & \multicolumn{1}{c}{ Tingkat Pendidikan } & Frekuensi & Frekuensi Relatif $(\boldsymbol{\%})$ & $\Delta$ \\
\hline 1 & SMP/MTs & 3 & 21.43 & 1.00 \\
2 & SMA/MAN & 9 & 64.29 & 0.62 \\
3 & Perguruan Tinggi (PT) & 2 & 14.29 & - \\
\hline
\end{tabular}

Distribusi penelitian media pembelajaran biologi berdasarkan tingkat Pendidikan ditunjukkan pada Tabel 3. Tabel 3 tingkat Pendidikan SMA/MA dan SMP/MTs menunjukkan adanya pengaruh positif dari media pembelajaran terhadap hasil belajar, pada PT belum ada data pendukung untuk perhitungan effect size. Selain itu, penelitian tentang media pembelajaran biologi paling banyak dilakukan pada tingkat SMA/MA yaitu 64,29\%, disusul penelitian di tingkat SMP/MTs sebanyak 21,43\%. Data pengujian media pembelajaran menunjukkan lebih baik pada SMP/MTs masuk kategori efek tinggi $(1,00)$ dan implementasi media pembelajaran pada SMA/MA 
menunjukkan efek sedang $(0,62)$. Sedangkan, implementasi pada perguruan tinggi belum ada data hasil pengujian kuantitatif. Peserta didik SMP/MTs merupakan remaja yang penuh dengan rasa ingin tahu yang berkembang penelaranya dari konkret menuju kemampuan penalaran abstrak sehingga media pembelajaran bagi SMP/MTs akan lebih efektif.

Tabel 4. Distribusi Jenis Media

\begin{tabular}{clccc}
\hline No. & \multicolumn{1}{c}{ Jenis Media } & Frekuensi & Frekuensi Relatif (\%) & $\Delta$ \\
\hline 1 & Audio visual/Video & 3 & 21.43 & 0.78 \\
2 & Torso & 1 & 7.14 & 0.00 \\
3 & Genetic Vocabuary Card & 1 & 7.14 & - \\
4 & Powerpoint & 1 & 7.14 & 0.94 \\
5 & Media Berbasis Android & 1 & 7.14 & 0.00 \\
6 & Multimedia & 3 & 21.43 & 2.00 \\
7 & Blended Learning Media & 1 & 7.14 & - \\
8 & Media pembelajaran & 1 & 7.14 & - \\
\hline
\end{tabular}

Distribusi jenis media dan effect size ditunjukkan pada Tabel 4 berikut. Penelitian dengan data yang mendukung perhitungan effect size menunjukkan pengaruh positif media, kecuali pada media berbasis android. Hal tersebut dapat disebabkan karena penerapan media tersebut pada materi biologi kelas 10 (sepuluh) yang begitu banyak dan rancangan media yang kurang ramah pengguna. Tabel 4 menunjukkan jenis media pembelajaran yang paling digunakan adalah media audio visual/video dan multimedia yaitu masing-masing sebanyak $23,43 \%$. Hal tersebut disebabkan karena dalam materi biologi lebih banyak materi berupa teori, konsep, proses, dan beberapa perhitungan sederhana yang tentunya lebih mudah dijelaskan dalam bentuk media audio visual misalnya sistem organ, ekologi, dan genetika. Multimedia lebih mudah digunakan dengan melibatkan proses uji konsep setelah suatu materi dipelajari oleh peserta didik, yang dapat dibuat menggunakan adobe flash. Hal tersebut diperkuat dengan efect size tertinggi ditunjukkan pada penelitian yang mengimplementasikan media pembelajaran biologi berupa multimedia yaitu 2,00 masuk kategori effect size dengan pengaruh yang tinggi. Multimedia merupakan media pembelajaran yang di dalamnya mengandung berbagai media baik audio, visual, dan atau kuis/tes yang umumnya ditampilkan secara interaktif dan ramah pengguna. Multimedia memudahkan peserta didik dalam memahami konsep materi maupun mengecek penguasaan materinya. Sehingga, memberikan peserta didik belajar mandiri dan mengevaluasi diri apakah perlu mengulang pembelajaran atau sudah cukup dengan pemaham konsep yang dimilikinya. Salah satu multimedia interaktif yang kreatif dikembangkan oleh Indrawan, dkk (2019) yaitu multimedia interaktif yang mendukung pembelajaran offline maupun online yang selanjutnya didefinisikan sebagai Blended Learning Media (BLM) yang agak berbeda dengan Nurhikmah. Dkk (2018) yang lebih menunjuk BLM adalah media pendukung blended learning. Penerapan media pembelajaran biologi khususnya yang berbasis digital harus memperhatikan ketersediaan peralatan memadai seperti laboratorium computer/laptop, ruangan media, alat proyektor (infokus), kertas bidang infokus dan adanya sumber arus listrik (Karno, 2015). Multimedia interaktif banyak dikembangkan dalam penelitian menggunakan macromedia flash professional.

Tampilan menarik meningkatkan motivasi peserta didik untuk belajar dan meningkatkan pemahaman terhadap materi yang sedang di ajarkan serta sangat efektif dijadikan sumber belajar (Karno, 2015). Perkembangan ilmu pengetahuan dan teknologi (IPTEK) memberikan tantangan tersendiri bagi guru untuk menciptakan media pembelajaran yang dapat meningkatkan mutu pendidikan yang lebih baik. berkembangnya IPTEK mendorong guru untuk menghasilkan media pembelajaran berbasis computer salah satunya dalam bentuk multimedia (Muyaroah \& Mega, 2017). Pembelajaran Biologi ini bisa memanfaatkan media komputer yang dapat disajikan dengan menggunakan multimedia agar pembelajaran Biologi lebih menarik lagi untuk dipelajari dan lebih nyata tanpa khayalan dengan menampilkan video, gambar, dan foto (Tasmalina \& Pandu Prabowo, 2018). Pemanfaatan Media Video pada multimedia pembelajaran diharapkan dapat mempersingkat proses pembelajaran agar lebih efesien, khususnya terkait praktek biologi. Namun, hal ini dapat berdampak pada menurunnya kreativitas peserta didik karena kurangnya pengalaman belajar praktikum secara langsung. Media pembelajaran ini salah satu komponen proses belajar mengajar yang memiliki peranan sangat penting dalam menunjang keberhasilan proses belajar mengajar hal tersebut dengan pendapat Gagne (Rena Agustina \& Harun Sitompul, 2015) menyatakan bahwa media merupakan komponen-komponen di lingkungan belajar peserta didik yang merangsang peserta didik untuk belajar dengan baik. Multimedia memadukan berbagai media untuk menyampaikan materi dengan terstruktur dan desain yang menarik sehingga merangsang peserta untuk belajar lebih tekun dan tidak mudah bosan karena adanya ilustrasi yang menarik. Pesan dan informasi yang didapat disalurkan melalui media pembelajaran dapat berupa pesan verbal dan non verbal yang mengandalkan baik penglihatan maupun pendengaran (Sari, dkk., 2017). Media pembelajaran penting digunakan sesuai konsep paradigma pembelajaran dari behavioristik ke konstruktivistik. Pembelajaran konstruktivistik menuntut siswa agar mampu mengembangkan pengetahuan sendiri dan belajar mandiri. Perubahan paradigma ini telah merubah pemahaman tentang pembelajaran, yaitu dari pengajaran (teaching) yang berpusat pada guru ke pembelajaran (learning) berpusat pada siswa (Sari, dkk., 2017). 
Tabel 5. Distribusi Materi

\begin{tabular}{clccc}
\hline No. & \multicolumn{1}{c}{ Materi } & Frekuensi & Frekuensi Relatif (\%) & Efect Size \\
\hline 1 & Sistem Gerak & 1 & 7.14 & 1.11 \\
2 & Sistem Pencernaan & 1 & 7.14 & 0.94 \\
3 & Genetika & 1 & 7.14 & - \\
4 & Spermathopyta & 1 & 7.14 & 2.00 \\
5 & Sistem Peredaran Darah & 1 & 7.14 & 0.37 \\
6 & Pertumbuhan dan perkembangan & 1 & 7.14 & - \\
7 & Biologi kelas 10 & 1 & 7.14 & 0.00 \\
8 & Mikrobiologi & 1 & 7.14 & - \\
9 & Genetika & 1 & 7.14 & - \\
10 & Reproduksi & 1 & 7.14 & - \\
11 & Biologi kelas 11 & 1 & 7.14 & 1.18 \\
12 & Ekosistem & 1 & 7.14 & - \\
13 & Pernapasan & 2 & 14.29 & - \\
\hline
\end{tabular}

Jenis materi yang digunakan sebagai konten dalam penelitian media pembelajaran biologi sangatlah bervariasi (ditunjukkan pada Tabel 5). Tidak semua media pembelajaran memiliki data yang mendukung perhitungan effect size, materi dengan effect size positif antara lain materi Spermathopyta, system pencernaan, system gerak, system peredaran darah, dan ekosistem. Efect size tertinggi ditunjukkan pada media pembelajaran dengan materi Spermathopyta masuk kategori effect size dengan pengaruh yang tinggi $(2,00)$, diikuti materi ekosistem $(1,18)$ dan system gerak $(1,11)$ yang masuk kategori effect size sangat tinggi. Media pembelajaran dengan materi Spermathopyta dikembangkan dalam bentuk media pembelajaran multimedia interaktif yang memudahkan peserta didik dalam menguasai konsep dan juga mengevaluasi pemahaman konsepnya. Hal tersebut tentu memudahkan peserta didik dalam mempelajari materi Spermathopyta. Ketepatan pembuatan media pembelajaran pembelajaran dengan jenis dan karakteristik materi sangatlah penting untuk menghasilkan proses belajar yang optimal selain kebutuhan peserta didik. Tidak semua jenis media efisien untuk semua jenis materi biologi, sangat tergantung dari karakteristik materi. Spermathopyta sebagai materi yang banyak melibatkan konsep dan deskripsi sangat baik menggunakan media video, gambar, yang dilengkapai dengan tes pemahaman konsep yang terdapat pada multimedia. Selain, itu gaya belajar peserta didik juga perlu dipertimbangkan dlam pembuatan media pembelajaran (Rena Agustina \& Harun Sitompul, 2015). Media pembelajaran merupakan alat bantu proses belajar untuk memperoleh pengalaman tidak langsung. Media pembelajaran sangat membantu proses pembelajaran biologi karena tidak semua materi biologi dapat kita pelajari dari lingkungan kita, apalagi kalua sekolah tidak memiliki fasilitas laboratorium yang lengkap khususnya media berbasis IT. Minimal dengan media pembelajaran peserta didik dapat ditunjukkan torso, gambar dan atau video terkait materi biologi. Pada fasilitas yang lebih modern pembelajaran biologi dibantu dengan media yang berbasis online, yang dapat diakses oleh peserta didik dimanapun dan kapanpun mereka ingin belajar, tanpa harus membawa buku. Media pembelajaran memberikan peluang peserta didik untuk belajar lebih mandiri, melakukan repetisi setelah evaluasi, dan melakukan pengkayaan pemahaman dengan mengeksplor lebih jauh materi yang dipelajari. Hal tersebut menyebabkan penerapan media pembelajaran biologi dapat meningkatkan hasil belajar peserta didik (Candra Utama, Sri Kentjananingsih, \& Yuni Sri Rahayu, 2014).

Proses pembelajaran biologi sering dihadapkan pada materi yang tidak dapat divisualisasikan secara langsung sehingga sulit dipahami peserta didik (Mukti \& Nurcahyo, 2017). Beberapa yang sulit divisualisasikan secara langsung antara lain anatomi dan fisiologi manusia, jaringan, sel, evolusi, genetika, taksonomi dan asalusul mahluk hidup. Kesulitan ini yang kemudian diatasi dengan menggunakan media pembelajaran (Mukti \& Nurcahyo, 2017). Selanjutnya dinyatakan, media pembelajaran merupakan unsur yang sangat penting dalam pembelajaran. Salah satu fungsi utama media pembelajaran adalah sebagai alat bantu mengajar yang turut memotivasi, mempengaruhi iklim, kondisi, dan lingkungan belajar yang ditata dan diciptakan oleh guru.

\section{Simpulan}

Berdasarkan hasil dan pembahasan dapat disimpulkan: (1) jenis penelitian yang terkait dengan media pembelajaran biologi antara lain eksperimen, R \& D, deskriptif kuantitatif dan deskriptif kualitatif; (2) effect size media pembelajaran biologi berdasarkan tingkat pendidikan terbaik pada SMP/MTs $(1,00)$ masuk kategori tinggi; (3) effect size media pembelajaran biologi berdasarkan jenis media terbaik pada multimedia $(1,00)$ masuk kategori effect size dengan pengaruh yang tinggi; (4) effect size media pembelajaran biologi berdasarkan materi terbaik pada Spermathopyta $(2,00)$ masuk kategori effect size dengan pengaruh yang tinggi.

Berdasarkan simpulan tersebut dapat disarankan untuk penelitian selanjutnya sebaiknya: (1) penelitian media pembelajaran dikembangkan dengan $\mathrm{R} \& \mathrm{D}$ dengan pengujian yang lebih lengkap dan lebih baik; (2) implementasi media pembelajaran terbaik diperoleh dari penelitian pada tingkat Pendidikan SMP/MTs, pada SMA dan PT dapat dilakukan analisis kebutuhan yang lebih mendalam agar media yang digunakan benar-benar efektif 
dan sesuai dengan psikologi dan kecenderungan pola belajarnya; dan (3) multimedia merupakan media pembelajaran yang paling efektif, multimedia selanjutnya dapat dikembangkan berupa multimedia yang daring, blended, atau berbasis android sehingga lebih mudah diakses oleh peserta didik.

\section{Daftar Pustaka}

Agus Ariyanto, Desy Fajar Priyayi, \& Lusiawati Dewi. (2018). Penggunaan Media Pembelajaran Biologi di Sekolah Menengah Atas (SMA) Swasta Salatiga. Bioedukasi Jurnal Pendidikan Biologi, 9(1), 1-13.

Arif Didik Kurniawan, Nuri Dewi Muldayanti, \& Banita Eka Putri. (2018). Developing flash media of quranicbased human reproduction system material. JPBI (Jurnal Pendidikan Biologi Indonesia), 4(3), 235-242.

Arifah Novia Arifin, Aldi, dan Fiska Indah Reski. (2018). Pengembangan Media Pembelajaran Genetic Vocabulary. Jurnal Sainsmat, 7(2), 177-184.

Candra Utama, Sri Kentjananingsih, \& Yuni Sri Rahayu. (2014). Penerapan Media Pembelajaran Biologi SMA Dengan Menggunakan Model Direct Instruction Untuk Meningkatkan Hasil Belajar. Jurnal Pena Sains, 1(1), 29-40.

Glass, G.V., McGraw B., \& Smith, M.L. (1981). Meta-Analysis in Social Research. Sage Publication.

Heinich. (2002). Intructional Media and Technology for Learning 7th edition. New Jersey: Prentice Hall, Inc.

Intan Nur Cahya Mukti \& Heru Nurcahyo. (2017). Pengembangan Media Pembelajaran Biologi Berbantuan Komputer untuk Meningkatkan Hasil Belajar Peserta Didik. Jurnal Inovasi Pendidikan IPA, 3(2), 137 149.

Intan Nur Cahya Mukti \& Heru Nurcahyo. (2017). Pengembangan Media Pembelajaran Biologi Berbantuan Komputer untuk Meningkatkan Hasil Belajar Peserta Didik. Jurnal Inovasi Pendidikan IPA, 3(2), 137 149.

Karno, R. (2015). Penerapan Media Pembelajaran Biologi dengan Menggunakan Macromedia Flash Profesional 8. Jurnal Ilmiah Edu Research, 2(1), 79-84.

Meta Puspa Sari, Siti Huzaifah, dan Lucia Maria Santoso. (2017). Pengaruh Penggunaan Media Video Terhadap Hasil Belajar IPA Biologi Siswa Kelas VIII di SMP Negeri 9 Palembang. Formatif: Jurnal Ilmiah Pendiikan MIPA, 7(3), 30-36.

Muhammad Isnaini, Indah Wigati, Resti Oktari. (2016). Pengaruh Penggunaan Media Pembelajaran Torso Terhadap Hasil Belajar Siswa Pada Materi Sistem Pencernaan Pada Manusia Di SMP Negeri 19 Palembang. Jurnal Biodata, 2(1), 82-91.

Nurhikmah H, Suradi Tahmir, Muhammad Junda, \& Baso Asrul N. Bena. (2018). Blended Learning Media in Biology Classroom. Journal of Physics: Conf. Series 1028, 2, 1-4.

P. Oktap Indrawan, M. Indra Wira Pramana, \& K. Dwi Hendratma Gunawan. (2019). Developing Tri Kaya Parishida Based Blended Learning Media Using Adobe Captive for Probstat Courses. Journal of Educational Research and Evaluation, 3(3), 157-171.

Primadya Anantyarta \& Ririn Listya Ika Sari. (2017). Keterampilan Kolaboratif dan Metakognitif Melalui Multimedia Berbasis Means Ends Analysis Collaborative And Metacognitive Skills Through Multimedia Means Ends Analysis Based. Jurnal Biologi dan Pembelajaran Biologi, 2(2), 33-43.

Rena Agustina \& Harun Sitompul. (2015). Pengaruh Media Pembelajaran dan Gaya Belajar Terhadap Hasil Belajar Biologi. Jurnal Teknologi Informasi \& Komunikasi dalam Pendidikan, 2(1), 1-14.

Siti Muyaroah \& Mega Fajartia. (2017). Pengembangan Media Pembelajaran Berbasis Android dengan menggunakan Aplikasi Adobe Flash CS 6 pada Mata Pelajaran Biologi. Innovative Journal of Curriculum and Educational Technology, 6(2), 79-83.

Tasmalina \& Pandu Prabowo. (2018). Pengaruh Media Video Pembelajaran Terhadap Hasil Belajar Siswa Pada Sub Materi Spermatophyta di SMA Swasta Nurul Amaliyah Tanjung Morawa Tahun Pembelajaran 2015/2016. BEST Journal, 1(1), 14-20.

Trio Ageng Prayitno \& Nuril Hidayati. (2017). Pengembangan Multimedia Interaktif Bermuatan Materi Mikrobiologi Berbasis Edmodo Android. Bioilmi, 3(2), 86-93.

Windy Agus Setiasih \& Dimara Kusuma Hakim. (2012). Pengembangan Media Pembelajaran Biologi Pokok Bahasan Ekosistem Guna Peningkatan Prestasi Siswa Kelas VII SMP Negeri 2 Sumbang. JUITA, 2(1), 9-20. 